\title{
Field validation of generic wind park models using fault records
}

\author{
Aboutaleb HADDADI ${ }^{1}$, Ilhan KOCAR ${ }^{1}$ (D), Thomas KAUFFMANN ${ }^{1}$, \\ Ulas KARAAGAC ${ }^{2}$, Evangelos FARANTATOS ${ }^{3}$, Jean MAHSEREDJIAN ${ }^{1}$
}

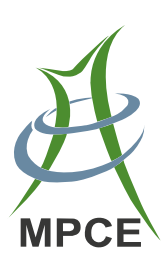

\begin{abstract}
A challenge faced by protection and planning engineers is the development and validation of accurate wind turbine generator (WTG) models to study the impact of increased wind integration on system protection. This paper is on the experimental validation of a generic electromagnetic transient-type (EMT-type) model of aggregated WTGs or wind parks suitable for transient studies. The phasor domain equivalent of the generic model, suitable for protection tools based on steady-state solvers, is also considered. The model has been validated using two sets of actual relay records for the fault response of two wind parks consisting of Type-III WTGs and connected to $115 \mathrm{kV}$ and $230 \mathrm{kV}$ transmission systems. The objective is to show that the generic model can reproduce the actual
\end{abstract}

CrossCheck date: 25 January 2019

Received: 15 November 2018/Accepted: 25 January 2019/Published online: 8 April 2019

(C) The Author(s) 2019

$\triangle$ Ilhan KOCAR

Ilhan.kocar@polymtl.ca

Aboutaleb HADDADI

aboutaleb.haddadi@polymtl.ca

Thomas KAUFFMANN

thomas.kauffmann@polymtl.ca

Ulas KARAAGAC

ulas.karaagac@polyu.edu.hk

Evangelos FARANTATOS

efarantatos@epri.com

Jean MAHSEREDJIAN

jean.mahseredjian@polymtl.ca

Polytechnique Montreal, Montréal, Canada

2 The Hong Kong Polytechnic University, Hong Kong, China

3 Electric Power Research Institute (EPRI), Palo Alto, USA fault response in simulations, and protection engineers can obtain accurate models of wind parks using fault records. A distinctive characteristic of a WTG is its substantially different negative sequence fault current contribution compared to a synchronous generator. The paper shows that the generic model provides enough options to reproduce the negative sequence behavior and hence is suitable for fault studies involving negative sequence-based protection.

Keywords Renewable generation, Wind turbine generator, Doubly-fed induction generator, Short-circuit analysis, Electromagnetic transient-type model, Phasor domain model

\section{Introduction}

A challenge faced by protection and planning engineers is to study the impact of increased renewable penetration on system protection [1-4]. The reason is that short-circuit models of conventional generators are not adequately representative of the substantially different, and in some cases complex, fault response of renewables. Power electronics associated with renewable generators produce current waveform signatures that are substantially different and in some cases more complex than those of conventional synchronous or asynchronous generators. To study the impact on protection, it is necessary to use sufficiently accurate models of renewables.

In previous papers, the authors have presented generic electromagnetic transient-type (EMT-type) models of aggregated wind turbine generators (WTGs) or wind parks suitable for transient studies for Type-III (doubly-fed induction generator, DFIG) and Type-IV (full-size 
converter, FSC) WTGs [5, 6]. These EMT-type models can emulate the time-domain fault response of an actual WTG. Taking these detailed models as references, phasor domain models were developed and an iterative algorithm to integrate these models into protection tools based on steady-state solvers was proposed [7-9]. The phasor models reproduce the steady-state short circuit behavior of detailed models.

This paper validates the Type-III generic model and its phasor equivalents using actual fault records of two wind parks consisting of Type-III WTGs and connected to 115 $\mathrm{kV}$ and $230 \mathrm{kV}$ transmission systems. The objective is to show qualitatively that the generic model and its phasor equivalent can reproduce the actual fault response in simulations. A simplified phasor model requiring less input is also proposed and validated.

A distinctive characteristic of a WTG is its substantially different negative sequence fault current contribution compared to a synchronous generator $[1,10]$, and it is necessary for a WTG model to account for the negative sequence behavior. The paper shows that the generic model can reproduce the negative sequence behavior and can be used for fault studies involving negative sequence-based protection.

This paper shows that it is possible to match the actual fault recordings using generic models once the pre-fault conditions are taken into account, and model parameters are properly set considering wind park controller and fault ride through (FRT) schemes. Therefore, it is possible for protection engineers to obtain precise models of their wind generation fleet by tuning generic models using fault records.

\section{Generic type-III WTG model}

References [5-9] have presented the generic Type-III WTG model used in this paper. This section presents a summary of the main features of the model.

Figure 1 shows a typical configuration for a Type-III WTG. The stator of the DFIG is directly connected to the

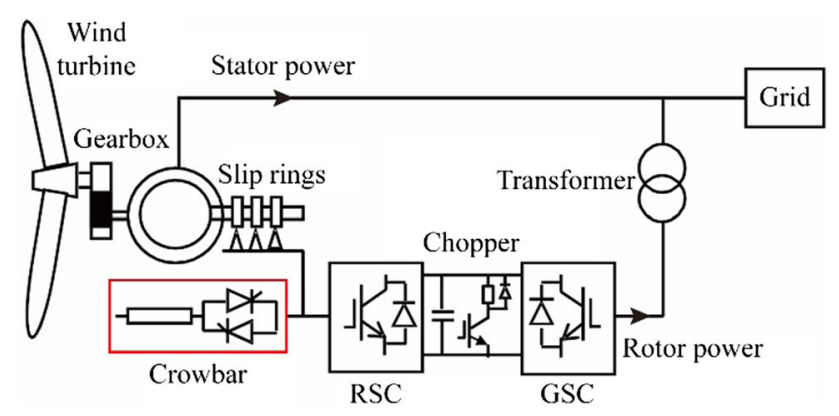

Fig. 1 Type-III WTG configuration grid, and the wound rotor is connected to the grid through a back-to-back converter system. The back-to-back converter system consists of two three-phase pulse-width modulated (PWM) converters, one rotor-side converter (RSC) and one grid-side converter (GSC) connected by a DC bus. A line inductor and an AC filter are used at the GSC to improve the power quality. A crowbar is used to protect the RSC against over-currents and the DC capacitors against overvoltages. During crowbar ignition, the RSC is blocked, and the machine behaves like a squirrel cage induction machine (consuming reactive power). Therefore, the DC resistive chopper is widely used to limit the DC voltage and avoid the crowbar ignition during $\mathrm{AC}$ faults.

The Type-III control is achieved by controlling the RSC and the GSC through vector control techniques. The RSC controls the active and reactive powers delivered to the grid and follows a tracking characteristic to adjust the generator speed for optimal power generation depending on the wind speed. On the other hand, the GSC is used to maintain the DC bus voltage at nominal value and regulate the positive sequence voltage at the medium-voltage side of wind turbine transformer. This objective is commonly achieved through a cascaded control structure consisting of an outer loop which regulates the DC and positive sequence voltage and an inner current loop which regulates the GSC current. The GSC has two control modes: coupled and decoupled sequences. In coupled sequence control mode, the objective is to fully eliminate the negative-sequence current which requires the converter to inject balanced three-phase currents even during unbalanced loading conditions or faults. To achieve this objective, the setpoints of the negative sequence $d$-axis and $q$-axis currents are set at zero while the set points of the positive-sequence $d$-axis and $q$ axis currents are determined based on the terminal voltage and reference power. The coupled sequence control results in second harmonic power oscillations in GSC power output under unbalanced loading conditions or faults which translates into second harmonic oscillations on the DC voltage and harmonic currents. To eliminate these oscillations, the decoupled sequence control injects a negative sequence current whose amplitude is proportional to the negative sequence terminal voltage. Thus, in contrast to coupled sequence control, under decoupled sequence control the converter must deliver negative-sequence current. For validation studies coupled sequence control mode is selected.

It should be noted that, it is possible to use the GSC to support the grid with reactive power during faults. Further, the same reactive power/AC voltage and power factor control schemes in the GSC control of Type-IV exist in the RSC of Type-III, and in the same way, these control modes are done on positive sequence parameters. For the two converters of one Type-III, the active power flow can be 
bidirectional. All the settings of the wind parks used for validation studies are provided in the Appendix A.

\section{Validation}

Two sets of actual relay recordings are available for the fault response of two wind parks consisting of Type-III WTGs and connected to $230 \mathrm{kV}$ and $115 \mathrm{kV}$ NorthAmerican transmission systems. Hereinafter in this paper, these two data sets are referred to as Fault $1(230 \mathrm{kV}$ system) and Fault 2 (115 kV system). The objective is to show that the detailed generic model can reproduce the fault recordings in simulations. The equivalent phasor domain model has been validated by showing that it matches the detailed model in steady state. Simulation tests have been carried on a model of the actual system including WTGs developed in EMTP [11].

\subsection{Fault 1}

Fault 1 is a fault in a $230 \mathrm{kV}$ transmission system close to a wind park. Figure 2 shows the system and the wind park which embeds $66 \times 1.5$ MW Type-III WTGs connected to a collector substation through three $34.5 \mathrm{kV}$ collector circuits and a $\mathrm{Y}-\Delta-\mathrm{Y}$ type $34.5 \mathrm{kV} / 230 \mathrm{kV}$ stepup transformer. An $18.7 \mathrm{~km}$ tie-line connects the collector substation to a $230 \mathrm{kV}$ point of interconnection (POI) substation. The fault is phase $\mathrm{B}$ to phase $\mathrm{C}$ occurring on the tie-line $3.5 \mathrm{~km}$ from the POI substation. Prior to the fault, all 66 WTGs were connected to the system, the park was delivering 25.69 MW and absorbing 1.35 Mvar from the $230 \mathrm{kV}$ system at the collector substation, and the wind speed was $6.5 \mathrm{~m} / \mathrm{s}$. The fault event was recorded by the line relays on the $230 \mathrm{kV}$ tie-line. The current differential relay systems that are applied to this line recorded the currents at both terminals in each relay.

A model of the system of Fault 1 has been developed in EMTP. The model represents the wind park by the generic aggregated model [5], the tie-line by a PI section, and the

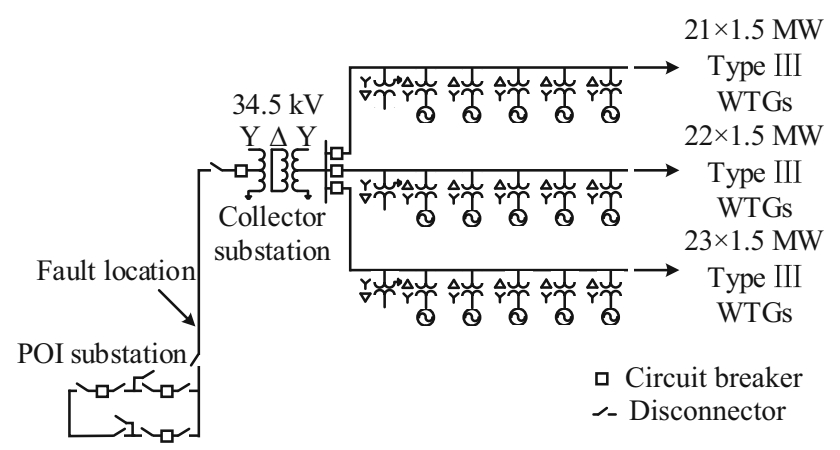

Fig. 2 Fault 1 in $230 \mathrm{kV}$ system rest of the transmission grid by an ideal-source behind an impedance. The fault has been simulated by connecting phases B and C of the PI section $3.5 \mathrm{~km}$ from the POI. The parameters of the actual wind park were not available. Therefore, the parameters of the generic model have been set to achieve maximum consistency between simulation results and fault recordings. Appendix A Table A1 presents the parameters of WTG model.

Figures 3, 4, 5, 6, 7 and 8 compare the actual response of the wind park recorded by the relays (dashed line) against the simulation results (solid line). The results are scaled so that the root-mean-square (RMS) magnitudes of

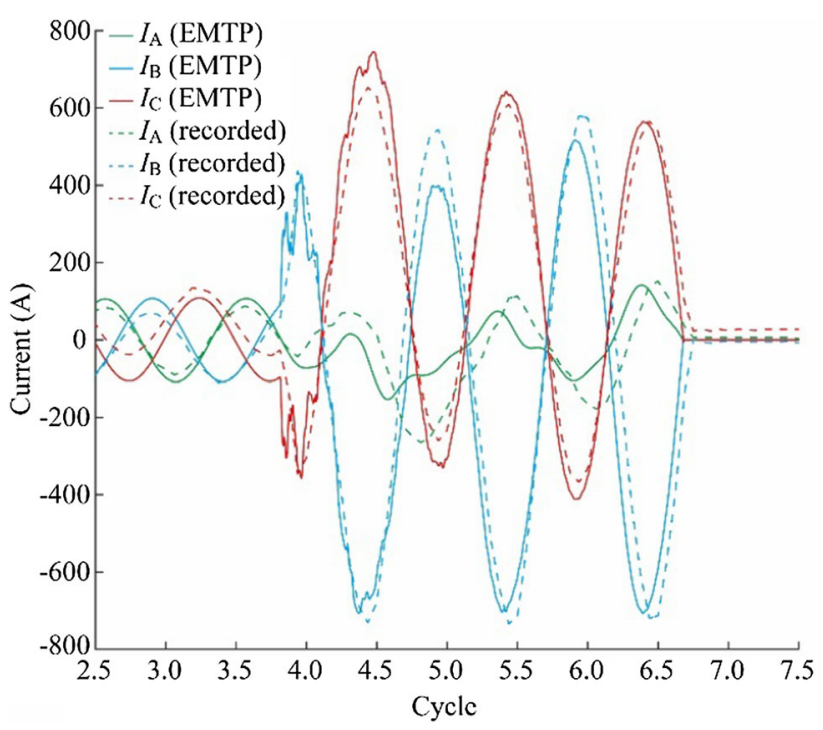

Fig. 3 Unfiltered phase currents from wind park measured at collector substation under Fault 1

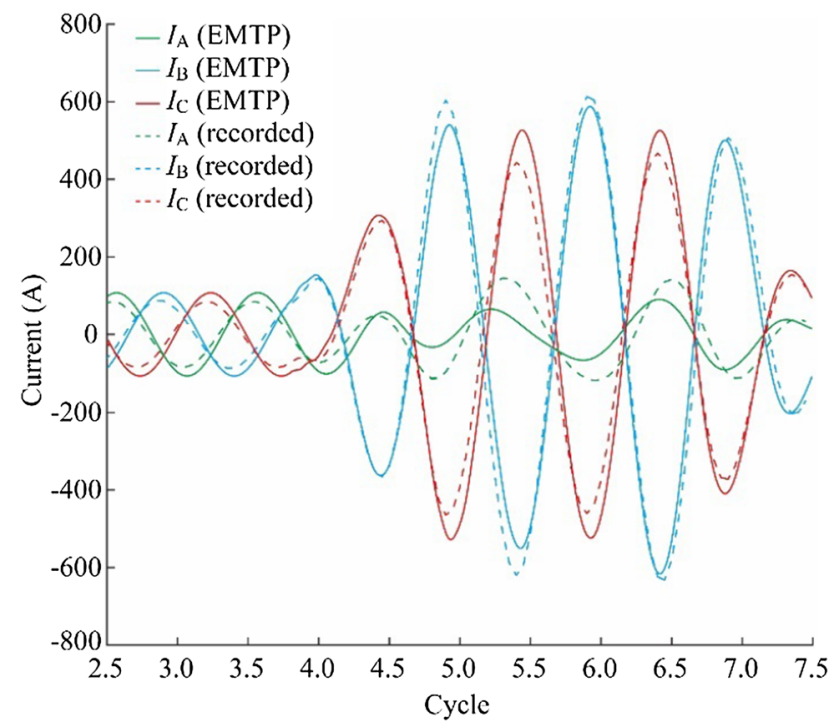

Fig. 4 Filtered phase currents from wind park measured at collector substation under Fault 1 


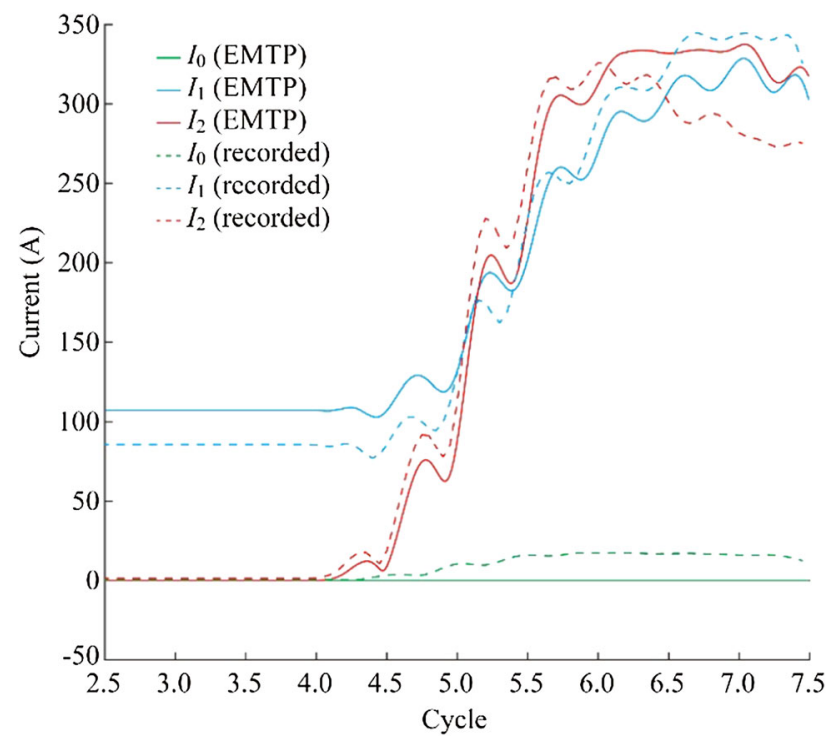

Fig. 5 Sequence currents from wind park measured at collector substation under Fault 1

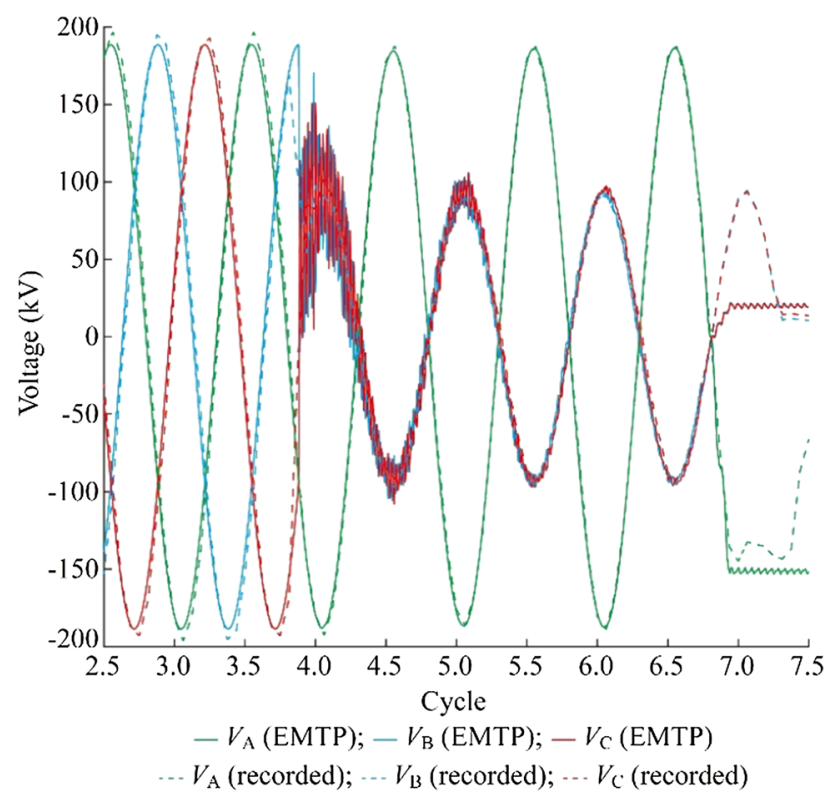

Fig. 6 Unfiltered phase voltages on line side of collector substation under Fault 1

the waveforms are displayed as peak values. The fault occurs 3.8 cycles into the simulation and is cleared within 3 cycles. The dashed line waveforms are recorded by the POI substation relay; they are sampled and processed by the wind park collector substation relay and transmitted to the POI substation relay. The tie-line is protected by a digital line current differential relay system, so the currents from both relays are recorded in either relay fault record.

Figure 3 illustrates the unfiltered phase currents from the wind park measured at the collector substation. Fig. 4

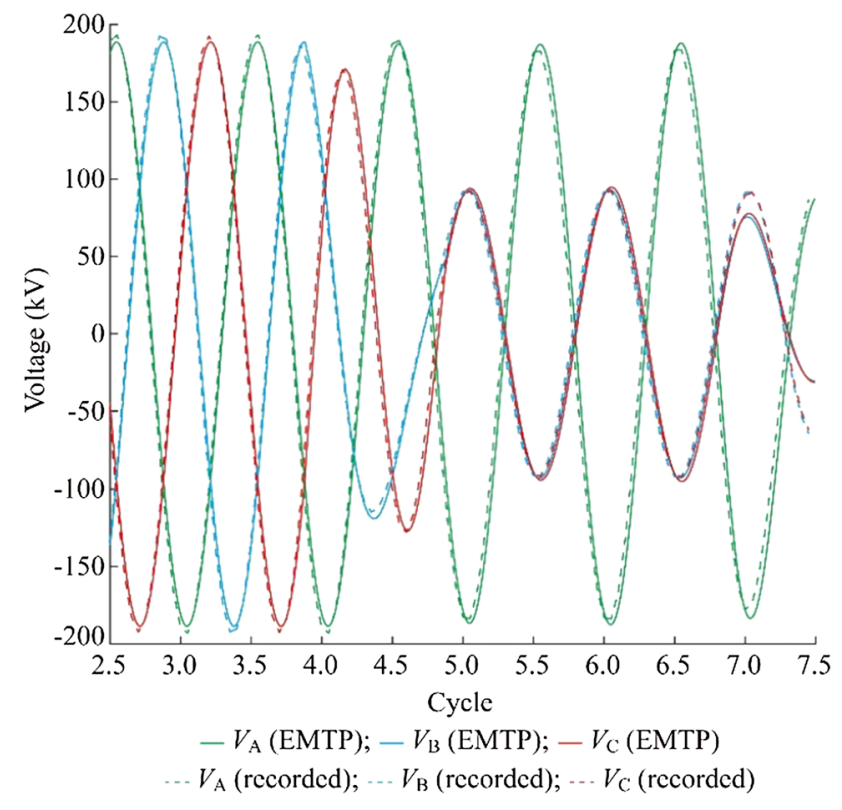

Fig. 7 Filtered phase voltages on line side of collector substation under Fault 1

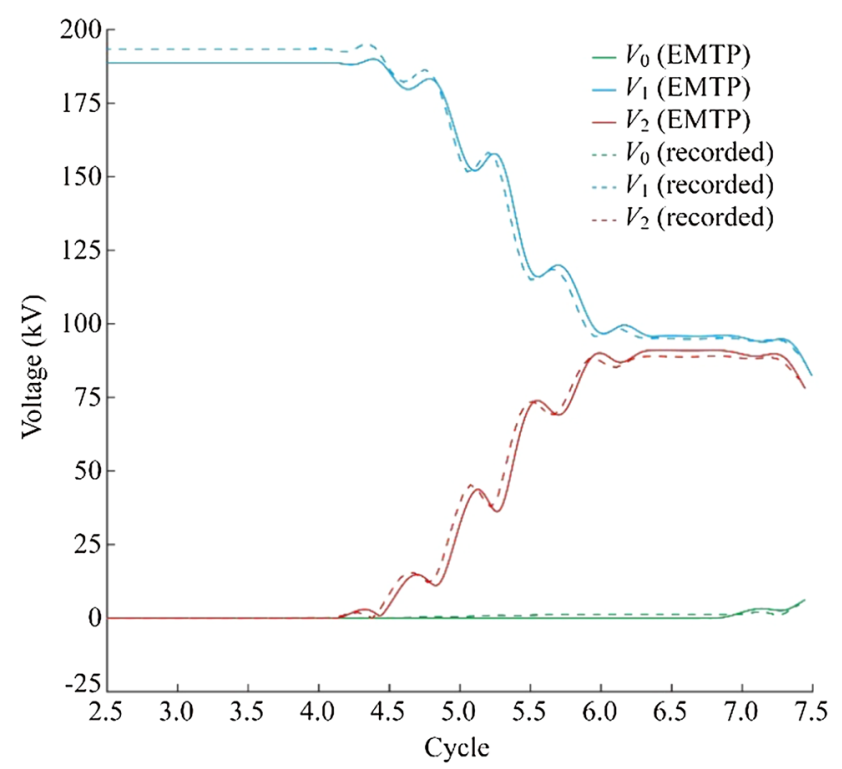

Fig. 8 Sequence voltages on line side of collector substation under Fault 1

presents the filtered phase current $(60 \mathrm{~Hz})$ from the wind park measured at the collector substation. Fig. 5 depicts the sequence currents (based on the $60 \mathrm{~Hz}$ component) from wind park measured at the collector substation. Fig. 6 shows the unfiltered phase voltages on the line side of the collector substation. Fig. 7 presents the filtered phase voltages $(60 \mathrm{~Hz})$ on the line side of the collector substation. Fig. 8 depicts the sequence voltages on the line side of the collector substation. As shown, the simulation results match closely the actual recordings. There are some 
differences particularly in the first cycle after the fault where high-frequency oscillations observed in simulations do not appear in the recorded data. The reason for this difference is that the sampling rate of the recordings is 16 samples per-cycle which is too low to capture these highfrequency oscillations. By contrast, the simulation sampling rate is 167 samples per cycle in EMTP and hence, the high-frequency oscillations manifest themselves in the simulation. Furthermore, some differences exist in the prefault current waveforms as the recorded currents are unbalanced while the simulated currents are balanced. The reason is that these imbalances were not modeled in the EMTP simulation model.

To validate the phasor domain equivalent model, Fault 1 has been simulated in phasor domain using the phasor domain model and the results have been compared to those of the generic EMT-type model. The simulation scenario is the same except that the fault is assumed to be permanent to enable comparison between the EMT-type and phasor domain results. The parameters of the phasor domain equivalent model are based on Appendix A Table A1.

Two versions of the phasor domain model have been tested: a detailed version as outlined in $[2,8,9]$ and a new simplified version as proposed in this work. They have two main differences: the first is the method of establishing the $d q$ reference frame of voltage and flux. The simplified model assumes the phase angle difference between the reference angle of voltage and flux $d q$ frame to be always $90^{\circ}$ whereas the detailed model represents this phase angle

Table 1 Positive and negative sequence currents $\left(I_{1}\right.$ and $\left.I_{2}\right)$ and voltages $\left(V_{1}\right.$ and $\left.V_{2}\right)$ at the terminal of GSC under Fault 1

\begin{tabular}{lcllc}
\hline Model & $I_{1}$ & $V_{1}$ & $I_{2}$ & $V_{2}$ \\
\hline EMT model & $0.768 \angle-$ & $0.640 \angle 12.0^{\circ}$ & $0.894 \angle 104.9^{\circ}$ & $0.317 \angle-$ \\
& $36.2^{\circ}$ & & & $5.3^{\circ}$ \\
Phasor model & $0.727 \angle-$ & $0.653 \angle 7.5^{\circ}$ & $0.882 \angle 100.2^{\circ}$ & $0.315 \angle-$ \\
(detailed) & $52.6^{\circ}$ & & & $3.3^{\circ}$ \\
Phasor model & $0.743 \angle-$ & $0.658 \angle 7.4^{\circ}$ & $0.900 \angle 98.0^{\circ}$ & $0.310 \angle-$ \\
(simple) & $53.8^{\circ}$ & & & $1.9^{\circ}$ \\
\hline
\end{tabular}

Table 2 Positive and negative sequence currents and voltages at collector under Fault 1

\begin{tabular}{lllll}
\hline Model & $I_{1}$ & $V_{1}$ & $I_{2}$ & $V_{2}$ \\
\hline EMT model & $\begin{array}{r}0.825 \angle- \\
39.7^{\circ}\end{array}$ & $0.509 \angle 1.5^{\circ}$ & $0.858 \angle 105.8^{\circ}$ & $0.488 \angle 0.4^{\circ}$ \\
& & & \\
Phasor model & $0.794 \angle-$ & $0.509 \angle 0.6^{\circ}$ & $0.845 \angle 100.8^{\circ}$ & $0.486 \angle 0.0^{\circ}$ \\
$\quad$ (detailed) & $55.3^{\circ}$ & & & \\
Phasor model & $0.810 \angle-$ & $0.509 \angle 0.6^{\circ}$ & $0.862 \angle 98.4^{\circ}$ & $0.486 \angle 0.1^{\circ}$ \\
$\quad$ (simple) & $56.4^{\circ}$ & & & \\
\hline
\end{tabular}

as a variable and calculates it using the parameters in detailed EMT-type model. This difference results in a discrepancy between the calculated $d$-axis and $q$-axis quantities of the simplified and detailed models. The second difference is the method of calculation of negativesequence current. The detailed model accurately reproduces the negative-sequence current of the EMT-type model and requires many inputs, whereas the simplified model estimates the negative sequence current using a

Table 3 Positive and negative sequence currents and voltages (RMS values) at collector under Fault 1

\begin{tabular}{lllll}
\hline Model & $I_{1}(\mathrm{~A})$ & $V_{1}(\mathrm{kV})$ & $I_{2}(\mathrm{~A})$ & $V_{2}(\mathrm{kV})$ \\
\hline EMT model & 228 & 67.60 & 237 & 64.80 \\
Phasor model (detailed) & 219.3 & 67.58 & 233.3 & 64.53 \\
Phasor model (simple) & 223.8 & 67.63 & 238.0 & 64.50 \\
\hline
\end{tabular}

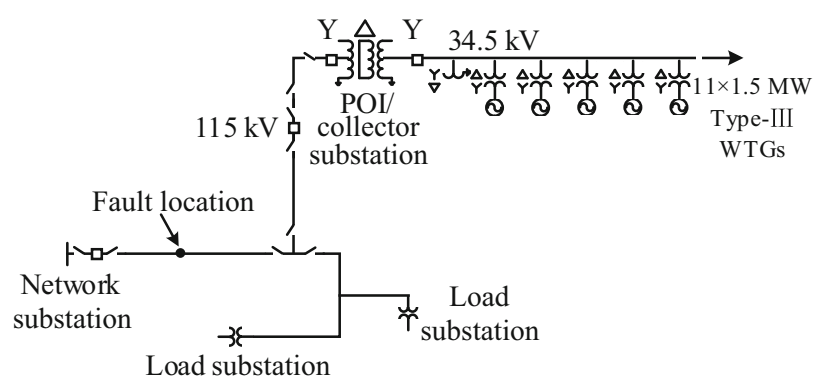

Fig. 9 Fault 2 in $115 \mathrm{kV}$ system

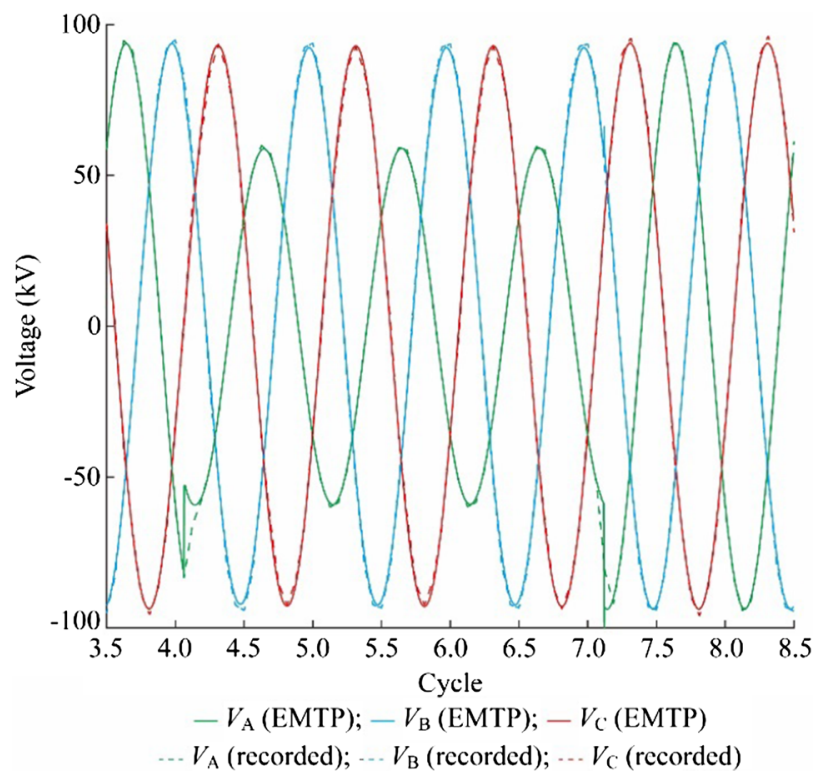

Fig. 10 Unfiltered phase voltages at network substation under Fault 2 


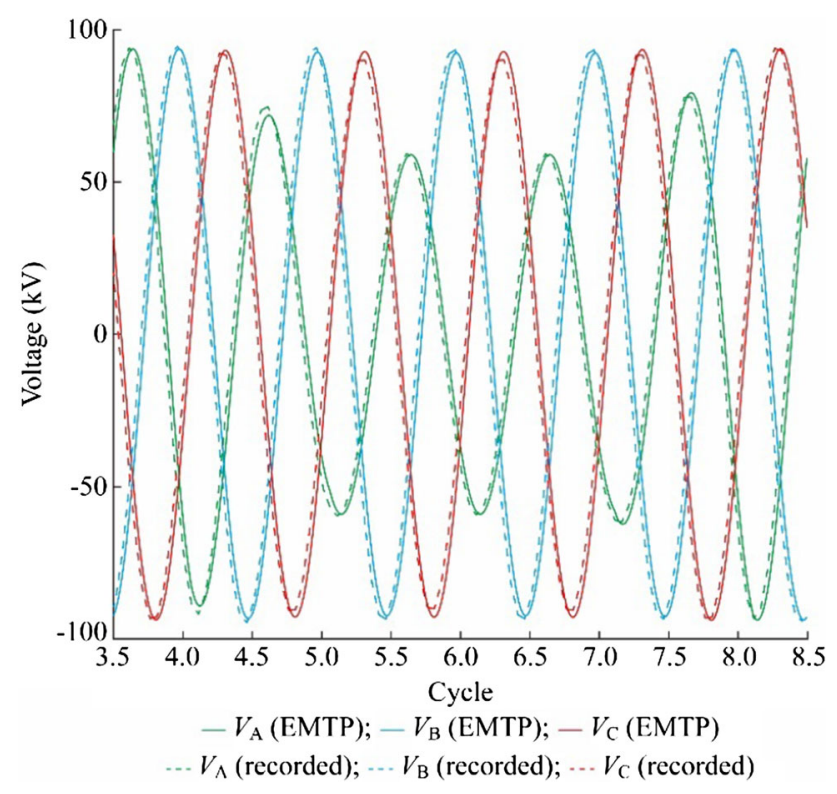

Fig. 11 Filtered phase voltages at network substation under Fault 2

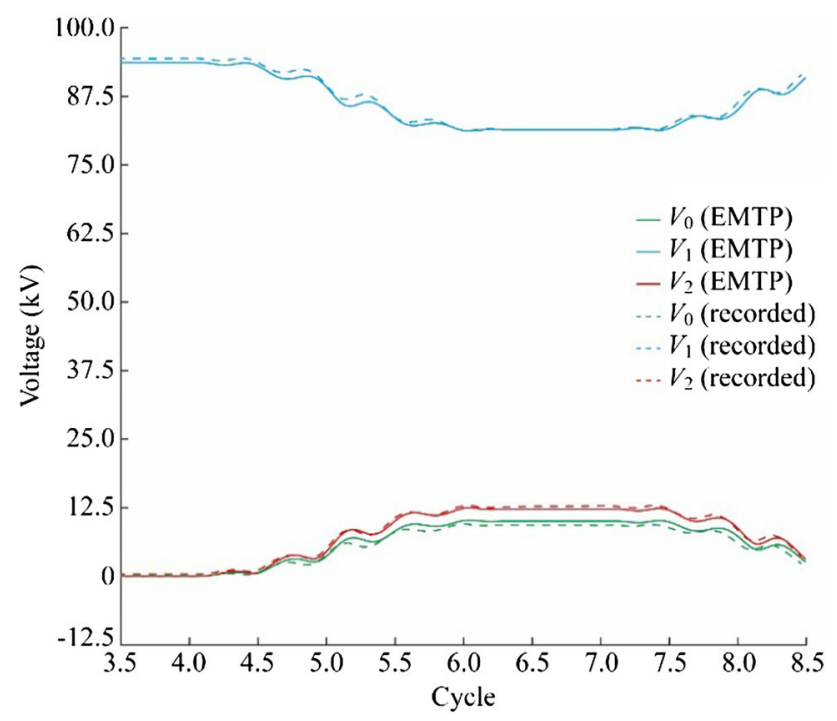

Fig. 12 Sequence voltages at network substation under Fault 2

simple relation that divides negative sequence voltage by equivalent machine impedance in [12].

Tables 1, 2 and 3 compare the simulation results of the EMT-type model and the phasor domain equivalent model suggesting a satisfactory match between the two models.

\subsection{Fault 2}

Fault 2 occurs close to a wind park in a $115 \mathrm{kV}$ transmission system. Figure 9 shows the system which is a portion of a $115 \mathrm{kV}$ transmission system. The wind park embeds $11 \times 1.5$ MW Type-III WTGs connected to a 34.5 $\mathrm{kV}$ collector circuit. A Y- $\Delta$-Y type $34.5 \mathrm{kV} / 115 \mathrm{kV}$ step-up

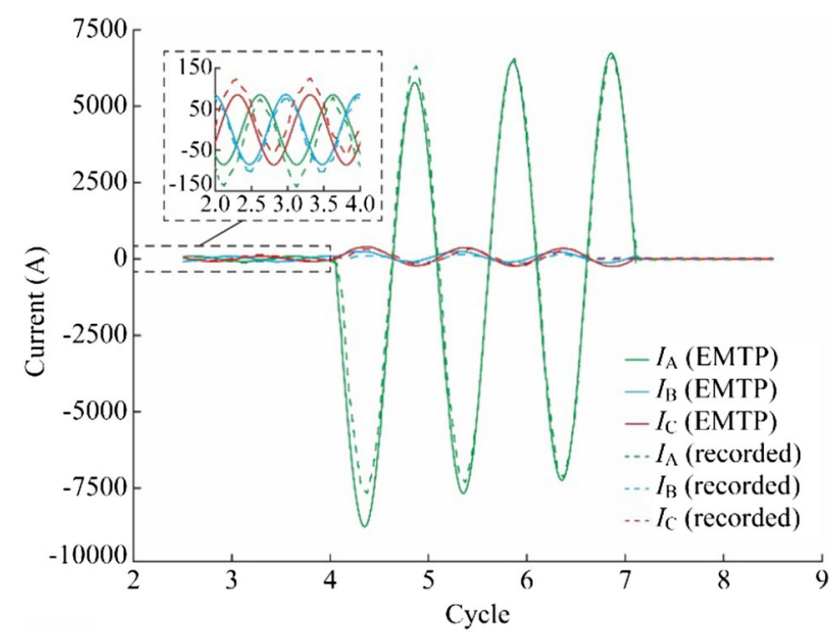

Fig. 13 Unfiltered phase currents from network substation under Fault 2

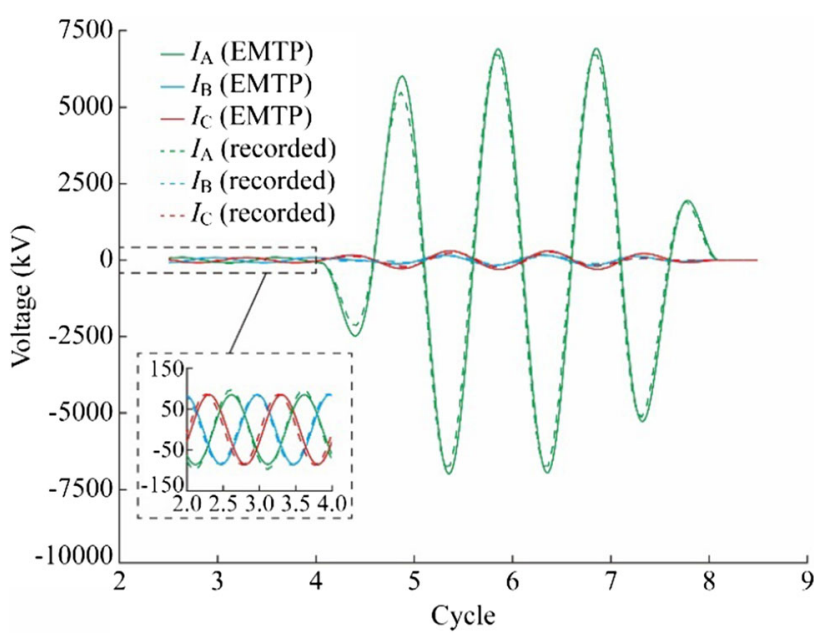

Fig. 14 Filtered phase currents from network substation under Fault 2

transformer connects the collector circuit to a $115 \mathrm{kV}$ POI/collector substation. A $10.7 \mathrm{~km}$ tie-line connects the POI/collector substation to a network substation. The fault was a phase A to ground occurring on the line to the network substation, $3.8 \mathrm{~km}$ from the network substation. Prior to the fault, all 11 WTGs were connected to the system, and the plant was supplying $17.7 \mathrm{MW}$ and 3.2 Mvar into the grid.

A model of the system of Fault 2 has been developed in EMTP. The model represents the wind park by the generic model [5], the tie-line by a PI section, and the rest of the transmission grid by an ideal-source behind an impedance. The fault has been simulated by connecting phase A of the PI section to the ground. Table 7 presents the parameters of the wind park model. 


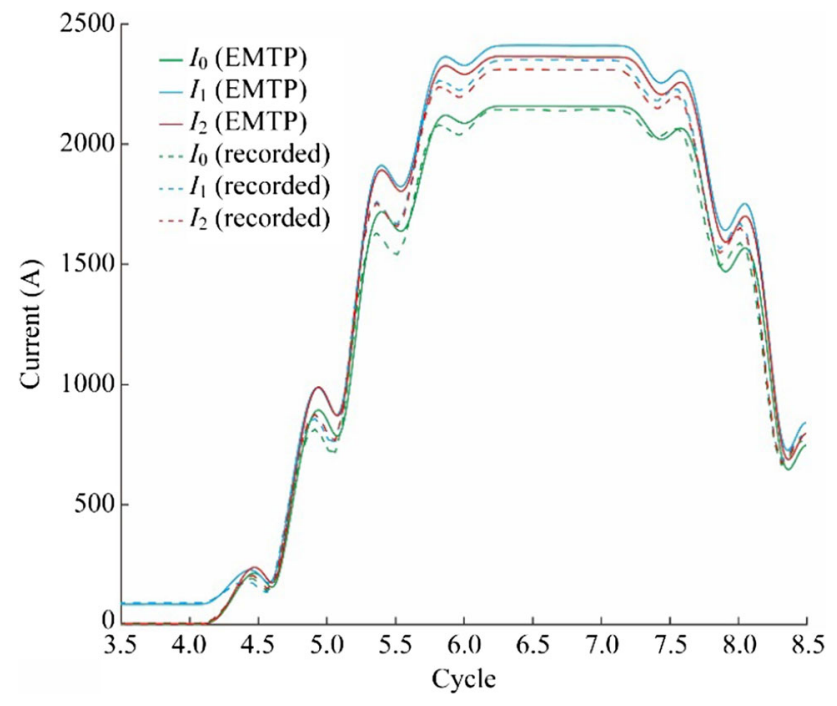

Fig. 15 Sequence currents from network substation under Fault 2

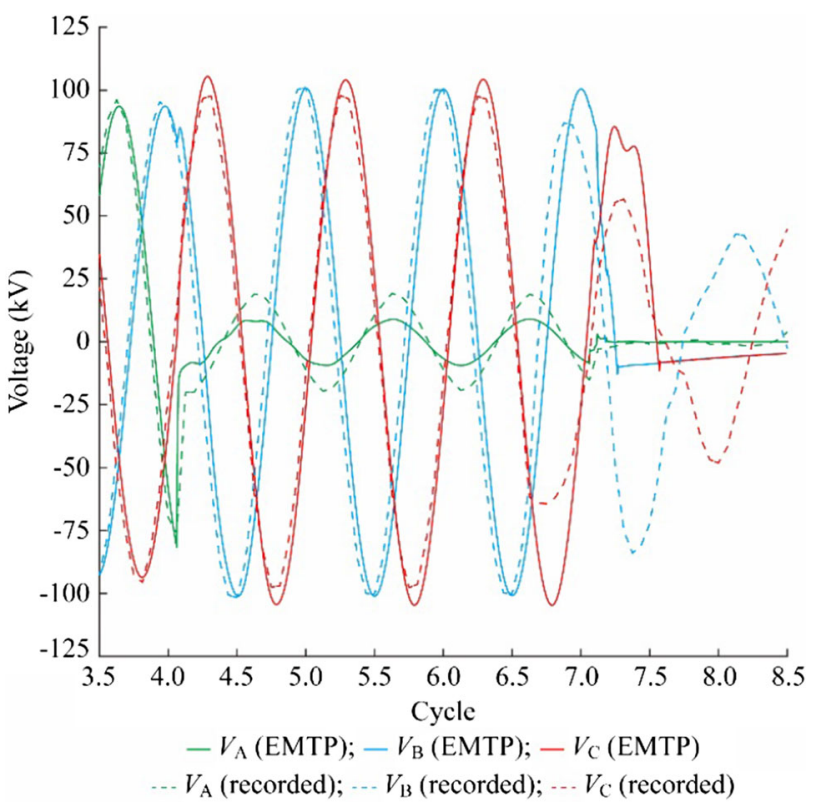

Fig. 16 Unfiltered phase voltages at POI/collector substation under Fault 2

Figures 10, 11, 12, 13, 14, 15, 16, 17, 18, 19, 20 and 21 compare the actual response of the wind park recorded by the relays (dashed line) against simulation results (solid line). The results are scaled so that the RMS magnitudes for the waveforms are displayed as peak values. The fault event was recorded by the line relays at the network and the $\mathrm{POI} /$ collector substations.

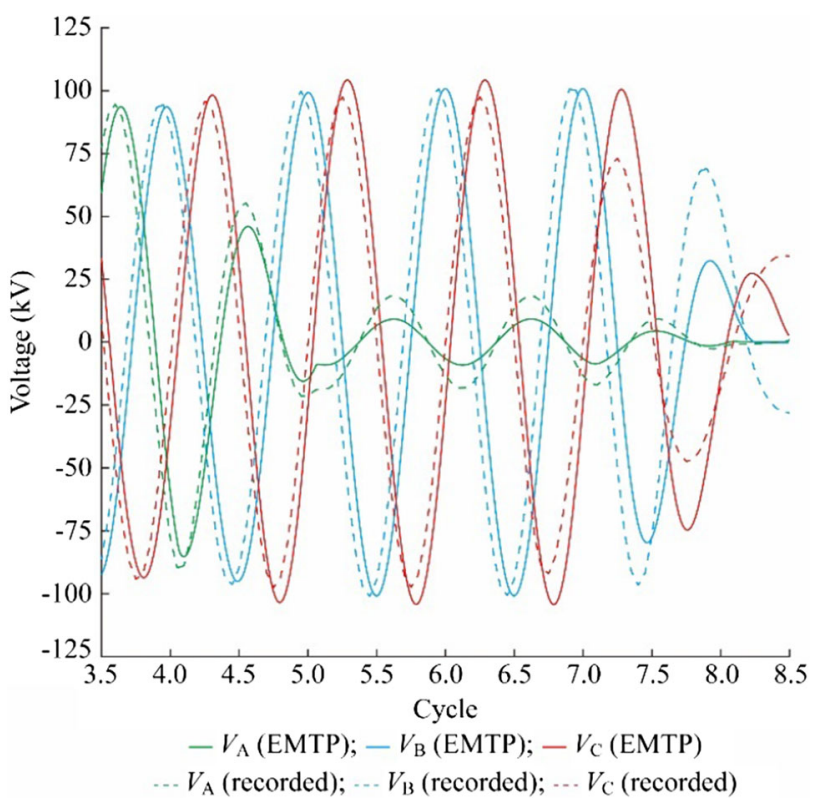

Fig. 17 Filtered phase voltages at POI/collector substation under Fault 2

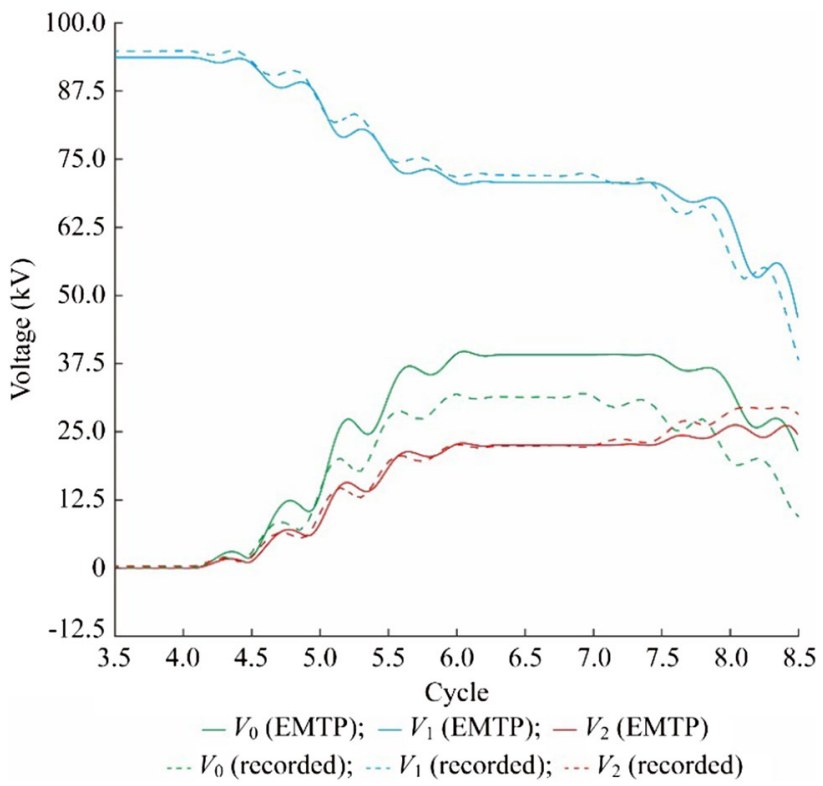

Fig. 18 Sequence voltages at POI/collector substation under Fault 2

Figures 10, 11 and 12 show the unfiltered, filtered (60 $\mathrm{Hz}$ ), and sequence components of phase voltages on the $115 \mathrm{kV}$ bus at the network substation. Figs. 13, 14 and 15 depict the unfiltered, filtered $(60 \mathrm{~Hz})$, and sequence components of phase currents from network substation. Figures 16, 17 and 18 illustrate the unfiltered, filtered (60 


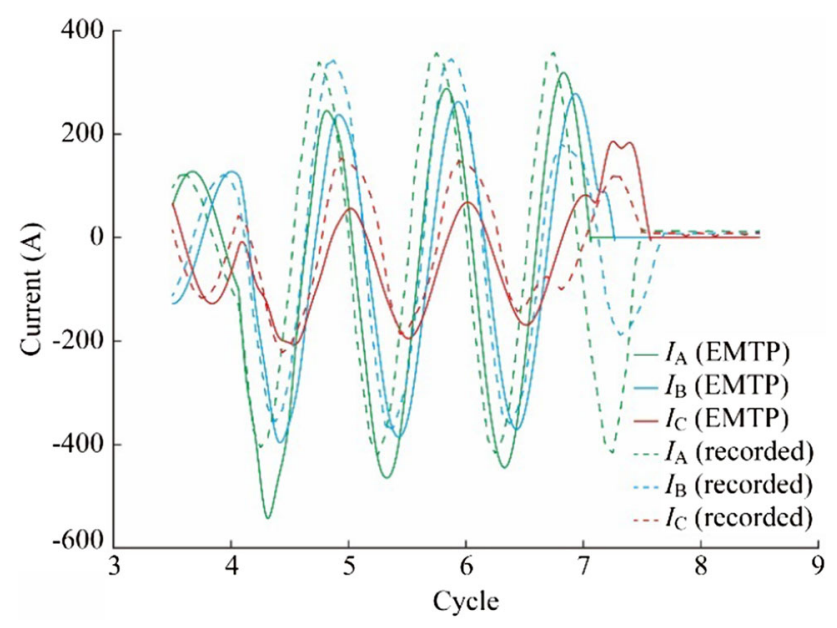

Fig. 19 Unfiltered phase currents from POI/collector under Fault 2

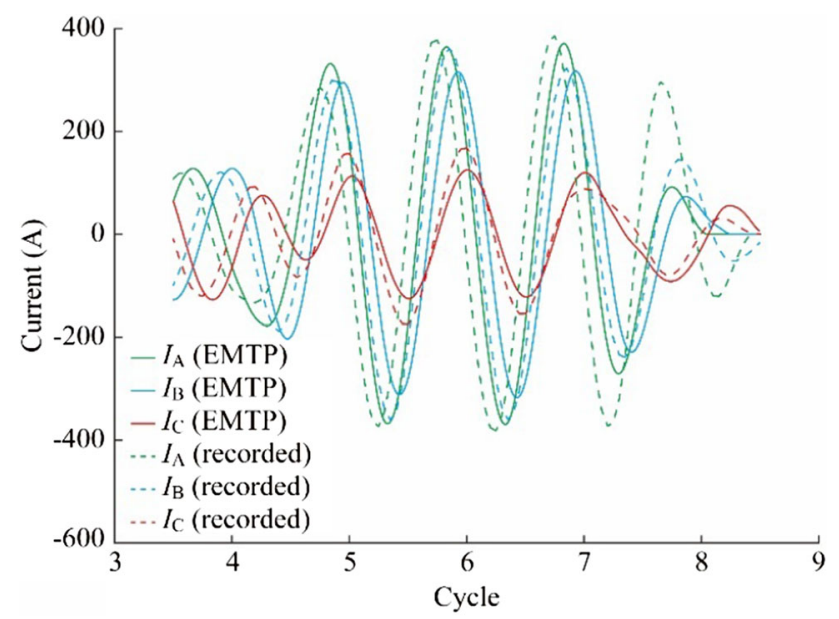

Fig. 20 Filtered phase currents from POI/collector substation under Fault 2

$\mathrm{Hz}$ ), and sequence components of phase voltages at the POI/collector substation. Figures 19, 20 and 21 present the unfiltered, filtered $(60 \mathrm{~Hz})$, and sequence components of phase currents from the POI/collector substation. As shown, the simulation results match the actual fault records.

Fault 2 has been simulated in phasor domain using the phasor domain equivalent model and the results have been compared to those of the EMT-type model. The simulation scenario is the same except that the fault is assumed to be permanent to enable comparison between the EMT-type and phasor domain results. The parameters of the phasor domain generic model are based on Appendix A Table A1.

Tables 4, 5 and 6 compare the simulation results of the EMT-type model and its phasor domain equivalent model. The results show a satisfactory match between the generic models.

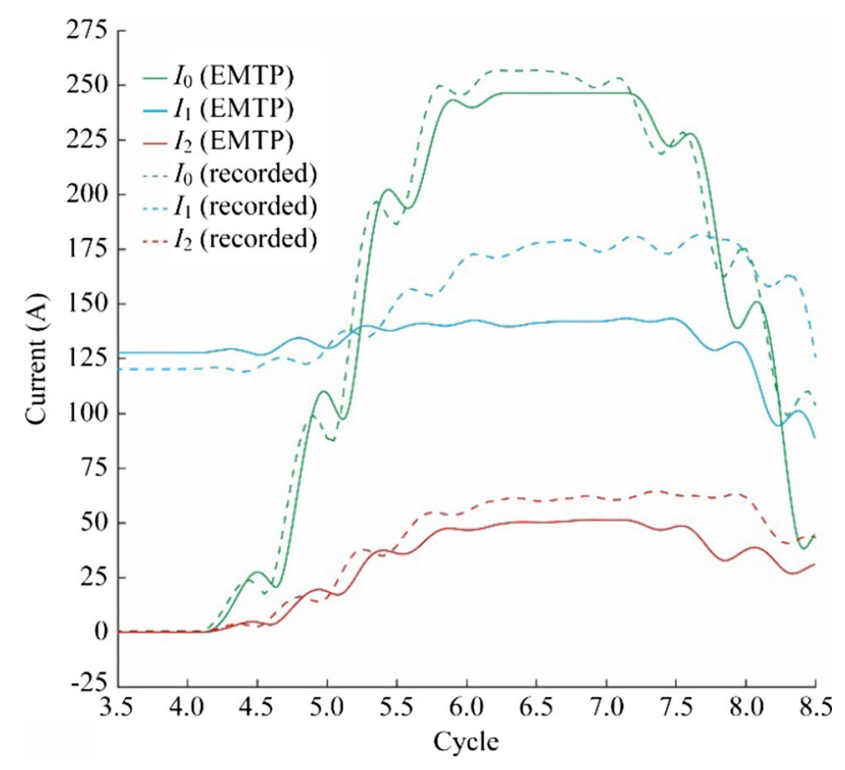

Fig. 21 Sequence currents from POI/collector substation under Fault 2

Table 4 Positive and negative sequence currents and voltages at the terminal of GSC under Fault 2

\begin{tabular}{lcccl}
\hline Model & $I_{1}$ & $V_{1}$ & $I_{2}$ & $V_{2}$ \\
\hline EMT model & $0.991 \angle-$ & $0.913 \angle 19.4^{\circ}$ & $0.431 \angle-$ & $0.133 \angle 174.6^{\circ}$ \\
& $7.5^{\circ}$ & & $78.4^{\circ}$ & \\
& & & \\
Phasor model & $0.967 \angle-$ & $0.923 \angle 18.1^{\circ}$ & $0.418 \angle-$ & $0.136 \angle 174.5^{\circ}$ \\
$\quad$ detailed) & $11.3^{\circ}$ & & $78.7^{\circ}$ & \\
Phasor model & $0.936 \angle-$ & $0.943 \angle 16.5^{\circ}$ & $0.404 \angle-$ & $0.139 \angle 178.0^{\circ}$ \\
(simple) & $17.1^{\circ}$ & & $82.2^{\circ}$ & \\
\hline
\end{tabular}

Table 5 Positive and negative sequence currents and voltages at POI/collector under Fault 2

\begin{tabular}{lclrr}
\hline Model & $I_{1}$ & \multicolumn{1}{l}{$V_{1}$} & \multicolumn{1}{l}{$I_{2}$} & \multicolumn{1}{l}{$V_{2}$} \\
\hline EMT model & $1.109 \angle-$ & $0.762 \angle 1.1^{\circ}$ & $0.394 \angle-$ & $0.242 \angle-$ \\
& $18.5^{\circ}$ & & $76.9^{\circ}$ & $178.0^{\circ}$ \\
Phasor model & $1.095 \angle-$ & $0.760 \angle 0.7^{\circ}$ & $0.380 \angle-$ & $0.241 \angle-$ \\
$\quad$ (detailed) & $22.3^{\circ}$ & & $77.1^{\circ}$ & $178.4^{\circ}$ \\
Phasor model & $1.082 \angle-$ & $0.762 \angle 0.6^{\circ}$ & $0.364 \angle-$ & $0.242 \angle-$ \\
$\quad$ (simple) & $28.0^{\circ}$ & & $81.2^{\circ}$ & $178.3^{\circ}$ \\
\hline
\end{tabular}

Table 6 Positive and negative sequence currents and voltages (RMS values) at POI/collector under Fault 2

\begin{tabular}{lrrrr}
\hline Model & \multicolumn{1}{c}{$I_{1}(\mathrm{~A})$} & $V_{1}(\mathrm{kV})$ & $I_{2}(\mathrm{~A})$ & $V_{2}(\mathrm{kV})$ \\
\hline EMT model & 102.10 & 50.60 & 36.30 & 16.10 \\
Phasor model (detailed) & 100.80 & 50.46 & 34.98 & 16.03 \\
Phasor model (simple) & 99.61 & 50.58 & 33.51 & 16.07 \\
\hline
\end{tabular}




\section{Conclusion}

This paper is on the validation of a generic aggregated wind park model for fault studies and its phasor domain equivalent model through cross-examination against actual fault records of two wind parks consisting of Type-III WTGs. The generic model is able to reproduce the timedomain response of the actual wind park to a fault. The phasor model provides the steady-state short-circuit response. A simplified phasor model is also proposed, in which less user input is required due to assumptions and simplifications in the model. It proved to be satisfactory within a margin of a few percent compared to the full phasor model.

Acknowledgements The authors would like to thank the members of the IEEE Power System Relaying and Control Committee (PSRC) for providing the measurement data [13].

Open Access This article is distributed under the terms of the Creative Commons Attribution 4.0 International License (http:// creativecommons.org/licenses/by/4.0/), which permits unrestricted use, distribution, and reproduction in any medium, provided you give appropriate credit to the original author(s) and the source, provide a link to the Creative Commons license, and indicate if changes were made.

\section{Appendix A}

See Table A1.

Table A1 Parameters of Type-III WTG model for Fault 1 and Fault 2 simulation cases

\begin{tabular}{|c|c|c|}
\hline \multicolumn{3}{|l|}{ Wind park } \\
\hline Fault & Fault 1 & Fault 2 \\
\hline Number of wind turbine units & 66 & 11 \\
\hline Frequency $(\mathrm{Hz})$ & 60 & 60 \\
\hline Collector grid nominal voltage (kV RMS) & 34.5 & 34.5 \\
\hline Transmission grid voltage (kV RMSL) & 230 & 115 \\
\hline \multicolumn{3}{|l|}{ Zig-zag transformer on collector grid } \\
\hline 0.1265 & & 0.1265 \\
\hline 0.3831 & & 0.3831 \\
\hline \multicolumn{3}{|l|}{ Single wind turbine parameters } \\
\hline Wind turbine generator type & Type-III & Type-II \\
\hline Wind turbine rated power (MVA) & 1.667 & 1.667 \\
\hline Wind turbine active power (MW) & 1.5 & 1.5 \\
\hline Generator nominal voltage (kV RMS) & 0.575 & 0.575 \\
\hline Filter reactive power (kvar) & 75 & 75 \\
\hline
\end{tabular}

Table A1 continued

\begin{tabular}{|c|c|c|}
\hline \multicolumn{3}{|l|}{ Equivalent collector grid } \\
\hline Resistance $(\Omega)$ & 0.1265 & 0.1265 \\
\hline Inductance $(\mathrm{mH})$ & 0.3831 & 0.3831 \\
\hline Capacitance $(\mathrm{mF})$ & 7 & 7 \\
\hline \multicolumn{3}{|l|}{ Operating conditions } \\
\hline Number of WTG units in service & 66 & 11 \\
\hline Operating mode & $Q$ control & $Q$ control \\
\hline$Q_{\text {ref }}(Q$ control setpoint) (p.u.) & -0.012 & 0.17 \\
\hline Wind speed $(\mathrm{m} / \mathrm{s})$ & 7.19 & 11.55 \\
\hline \multicolumn{3}{|l|}{ Wind park transformer } \\
\hline Connection type & Dyn11 & Dyn11 \\
\hline Nominal power (MVA) & 100 & 15 \\
\hline Turbine side voltage (kV RMS) & 34.5 & 34.5 \\
\hline Grid side voltage (kV RMS) & 230 & 115 \\
\hline Winding $R$ (p.u.) & 0.003 & 0.005 \\
\hline Winding $X$ (p.u.) & 0.12 & 0.18 \\
\hline \multicolumn{3}{|l|}{ Wind turbine transformer } \\
\hline Connection type & Dyn11 & Dyn11 \\
\hline Nominal power (MVA) & 1.75 & 1.75 \\
\hline Turbine side voltage (kV RMS) & 34.5 & 34.5 \\
\hline Converter side voltage (kV RMS) & 0.575 & 0.575 \\
\hline Winding $R$ (p.u.) & 0.002 & 0.002 \\
\hline Winding $X$ (p.u.) & 0.06 & 0.06 \\
\hline \multicolumn{3}{|l|}{ DFIG } \\
\hline Number of poles & 6 & 6 \\
\hline Stator winding resistance $R_{\mathrm{s}}$ (p.u.) & 0.033 & 0.033 \\
\hline Stator leakage inductance $L_{\mathrm{ls}}$ (p.u.) & 0.18 & 0.18 \\
\hline Magnetizing inductance $L_{\mathrm{md}}$ (p.u.) & 2.9 & 2.9 \\
\hline Magnetizing inductance $L_{\mathrm{mq}}$ (p.u.) & 2.9 & 2.9 \\
\hline Rotor resistance $R_{\mathrm{r}}$ (p.u.) & 0.026 & 0.026 \\
\hline Rotor leakage inductance $L_{\mathrm{lr}}$ (p.u.) & 0.16 & 0.16 \\
\hline Inertia constant $H_{\text {gen }}(\mathrm{s})$ & 0.9 & 0.9 \\
\hline Wind park controller & & \\
\hline$V$ control $K_{\mathrm{v}}$ (equals to FRT gain) & 2 & 2 \\
\hline$Q$ control $K_{\mathrm{p}}$ & 0 & 0 \\
\hline$Q$-control $K_{\mathrm{i}}(\mathrm{ms})$ & 0.15 & 0.15 \\
\hline Maximum voltage reference (p.u.) & 1 & 1 \\
\hline Minimum voltage reference (p.u.) & -1 & -1 \\
\hline Voltage reference rise time (s) & 0.05 & 0.05 \\
\hline FRT pickup voltage (p.u.) & 0.175 & 0.175 \\
\hline FRT reset voltage (p.u.) & 0.175 & 0.175 \\
\hline Rotor side converter control & & \\
\hline Converter model & Avera & alue model \\
\hline$V$-control $K_{\mathrm{V}}$ & 2 & \\
\hline
\end{tabular}


Table A1 continued

\begin{tabular}{lll}
\hline Rotor side converter control & & \\
\hline$P$-control $K_{\mathrm{p}}$ & 1 & 1 \\
$P$-control $T_{\mathrm{i}}(\mathrm{ms})$ & 0.1 & 0.1 \\
Rise time (ms) & 20 & 20 \\
Current limit (p.u.) & 1 & 1 \\
$q$-axis current limit (p.u.) & 1 & 1 \\
FRT current limit (p.u.) & 1.1 & 1.1 \\
FRT $d$-axis current limit (p.u.) & 1 & 1 \\
Minimum FRT voltage deviation (p.u.) & 0.1 & 0.1 \\
FRT reset voltage deviation (p.u.) & 0.075 & 0.075 \\
FRT reset delay (s) & 0.25 & 0.25 \\
\hline
\end{tabular}

Grid side converter control

\begin{tabular}{|c|c|c|}
\hline$V_{\mathrm{dc}}$ control $T_{\mathrm{i}}(\mathrm{ms})$ & 100 & 100 \\
\hline External system equivalent $R_{\text {sys }}(\Omega)$ & 8 & 8 \\
\hline External system equivalent $\underline{X}_{\text {sys }}(\Omega)$ & 31.5 & 31.5 \\
\hline Type of control & Coupled & Coupled \\
\hline Rise time (ms) & 10 & 10 \\
\hline $\begin{array}{l}\text { Current limit } \\
\text { (for decoupled control only) (p.u.) }\end{array}$ & 0.33 & 0.33 \\
\hline FRT current limit (p.u.) & 0.4 & 0.4 \\
\hline $\begin{array}{l}\text { FRT } q \text {-axis current limit } \\
\quad \text { (EMTP model mask) (p.u.) }\end{array}$ & 0.25 & 0.25 \\
\hline $\begin{array}{l}\text { FRT } d \text {-axis current limit } \\
\text { (phasor model mask) (p.u.) }\end{array}$ & 0.25 & 0.25 \\
\hline
\end{tabular}

\section{References}

[1] Haddadi A, Kocar I, Farantatos E et al (2017) System protection guidelines for systems with high levels of renewables: impact of wind and solar generation on negative-sequence and power swing protection. EPRI, USA

[2] Kocar I, Kauffmann T, Karaagac U et al (2017) Short-circuit phasor models of converter-based renewable energy resources for fault studies. EPRI, USA

[3] Haddadi A, Kocar I, Karaagac U et al (2017) Advanced shortcircuit modeling, analysis, and protection schemes design for systems with renewables - TVA case study. EPRI, USA

[4] Haddadi A, Kocar I, Karaagac U et al (2017) Impact of renewables on system protection: wind/PV short-circuit phasor model library and guidelines for system protection studies. EPRI, USA

[5] Teodorescu R, Liserre M, Rodriguez P (2011) Grid converters for photovoltaic and wind power systems. Wiley, USA

[6] Karaagac U, Saad H, Peralta J et al (2016) Doubly-fed induction generator-based wind park models in EMTP-RV. Dissertation, Montreal Polytechnique

[7] Karaagac U, Kauffmann T, Kocar I et al (2015) Phasor domain modeling of type-IV wind turbine generator for protection studies. In: Proceedings of IEEE PES general meeting, Denver, USA, 26-30 July 2015, 5 pp

[8] Kauffmann T, Karaagac U, Kocar I et al (2017) An accurate type III wind turbine generator short circuit model for protection applications. IEEE Trans Power Deliv 32(6):2370-2379
[9] Kauffmann T, Karaagac U, Kocar I et al (2015) Phasor domain modeling of type III wind turbine generator for protection studies. In: Proceedings of IEEE PES general meeting, Denver, USA, 26-30 July 2015, 5 pp

[10] Erlich I, Neumann T, Shewarega F et al (2013) Wind turbine negative sequence current control and its effect on power system protection. In: Proceedings of IEEE PES general meeting, Vancouver, Canada, 21-25 July 2013, 5 pp

[11] Mahseredjian J, Dennetière S, Dubé L et al (2007) On a new approach for the simulation of transients in power systems. Electric Power Systems Research 77(11):1514-1520

[12] Kauffmann T (2018) Modeling of wind parks for steady state short circuit studies. Dissertation, École Polytechnique de Montréal

[13] Barsch J, Bartok G, Benmouya G et al (2015) Fault current contributions from wind plants. In: Proceedings of annual conference for protective relay engineers, College Station, USA, 20 March-2 April 2015, 90 pp

Aboutaleb HADDADI received the B.Sc. and M.Sc. degrees in electrical engineering from Sharif University of Technology, Tehran, Iran, in 2007 and 2009, respectively, and the Ph.D. degree in electrical and computer engineering from McGill University, Montréal, Canada, in 2015. From 2015 to 2018, he was a postdoctoral fellow at Montréal Polytechnique, Montréal, Canada, where he is currently a research associate. He is the lead author of the CIGRÉ technical brochure power system test cases for EMT-type simulation studies. His research interests include power system stability and dynamics, system protection, power system simulation, renewable resource integration, and geomagnetic disturbance modeling and analysis.

Ilhan KOCAR received the B.Sc. and M.Sc. degrees in electrical and electronics engineering from Orta Dogu Teknik Universitesi (ODTU/METU), Ankara, Turkey, in 1998 and 2003, respectively, and the Ph.D. degree in electrical engineering from Polytechnique Montréal (affiliated with Université de Montréal), Canada in 2009. He worked as a Project Engineer at Aselsan Electronics Inc. (1998-2004) and as an R\&D Engineer at CYME International T\&D (2009-2011). He joined the faculty at Polytechnique Montreal in 2011. His career highlights include contributions to professional tools and development of models and solver prototypes for power systems analysis from steady state to electromagnetic transients. He has performed many grid consulting projects that cover design, modeling, analysis and validation of field measurements. His research interests include the development of concepts, models and methods for power system analysis and massive integration of renewables.

Thomas KAUFFMANN received his B.Sc. degree from École des Mines d'Albi-Carmaux, France, and M.Sc. degree from Polytechnique Montréal, Canada, in 2014. He received his Ph.D. degree from Polytechnique Montréal in 2018. He is currently working in an engineering consulting firm: BBA, in Mont-Saint-Hilaire, Quebec, Canada. His research interests include the control of electronically coupled generators (wind turbines and PVs) for steady-state shortcircuit modeling.

Ulas KARAAGAC received the Ph.D. degree in electrical engineering from Polytechnique Montreal (affiliated with Université de Montreal), Montreal, Canada, in 2011. He was an R\&D Engineer in the Information Technology and Electronics Research Institute, Ankara, Turkey (1999-2007). He was a Ph.D. scholar at Polytechnique Montreal between 2007 and 2011, where he continued working as a Postdoctoral Fellow and then as a Research Associate until the 
end of 2016. He joined the Department of Electrical Engineering of The Hong Kong Polytechnic University as a Research Assistant Professor in December 2016. His research interests include the integration of large-scale renewables into power grids, HVDC transmission, modeling and simulation of large scale power systems, and power system dynamics and control.

Evangelos FARANTATOS received the B.Sc. degree in electrical and computer engineering from the National Technical University of Athens, Greece, in 2006 and the M.Sc. and Ph.D. degrees from the Georgia Institute of Technology, Atlanta, USA, in 2009 and 2012, respectively. $\mathrm{He}$ is a Senior Technical Leader with the Grid Operations and Planning R\&D Group at EPRI, Palo Alto. In summer 2009, he was an intern at MISO. He is managing and leading the technical work of various R\&D projects related to synchrophasor technology, power systems monitoring and control, power systems stability and dynamics, system protection, state estimation, renewable energy resources modeling, DER integration, and grid operation with high levels of inverter based resources.

Jean MAHSEREDJIAN received the B.Sc degree from Polytechnique Montreal, Canada, and received the M.Sc. and Ph.D. degrees in 1985 and 1991, respectively. From 1987 to 2004, he was with IREQ (Hydro-Quebec), working on research and development activities related to the simulation and analysis of electromagnetic transients. In December 2004, he joined the Faculty of Electrical Engineering at Polytechnique Montreal, where he is currently a professor. 